\title{
Proxisome prolifrator-activated receptors alpha and delta in diabetic cardiomyopathy
}

\author{
Mahkameh Soltani ${ }^{1}$, Ramin Ataee $^{1,2^{*}}$ \\ ${ }^{1}$ Pharmacy, Faculty of Pharmacy, Mazandaran University of Medical Science, Sari, Iran \\ ${ }^{2}$ Pharmaceutical Sciences Research Center, Hemglobinopathy Institute, Mazandaran University of Medical Sciences, Sari, Iran \\ Received: Sep 7, 2015, Revised: Sep 26, 2015, Accepted: Nov 20, 2015
}

\begin{abstract}
Peraxisome prolifrator-activated receptors (PPARs) are a group of nuclear receptors comprising three isoforms termed alpha, beta/delta and gamma. PPARs can modulate metabolic processes especially fatty acid (FA) metabolisms via exerting transcriptional control on activating genes involved in fuel utilization. Thus, they can exert positive role in controlling chronic diseases such as diabetes. As development of diabetes leads to functional and structural alterations at the myocardium termed diabetic cardiomyopathy (DCM), metabolic controller seems to be able to affect on cardiomyocytes. Herein, the role of PPAR $\alpha$, and PPAR $\delta$, is emerged and compared. This minireview discusses about these receptors in diabetes.
\end{abstract}

Keywords: Peraxisome prolifrator-activated receptors (PPARs), metabolic processes, fatty acid (FA), diabetic cardiomyopathy (DCM), PPAR $\alpha$, PPAR $\delta$

Pharm Biomed Res 2015; 1(4): 1-11～DOI: 10.18869/acadpub.pbr.1.4.1

\section{Introduction}

As curve pertaining to morbidity and mortality of diabetes mellitus (DM) had positive slope in recent decades (1) and it is predicted to have 439 million diabetic patients in 2030 (2), more and more attention is paid to this issue. Additionally, myocardial dysfunctions such as diabetic cardiomyopathy (DCM) is more probable in DM patients compared to non-DMs (1). DCM is a pathological condition in which cardiomyocytes lose their potency to shift between different fuel substrate. Healthy heart uses long chain fatty acids (LCFA) providing $60-70 \%$ of ATP requirement to power contraction (3-6), but cardiac substrate utilization is altered in the diabetic condition leading excessive use of FA oxidation up to 90 $100 \%$ of the heart's ATP needs (5). As a result of metabolic derangements, myocardial dysfunction may appear. Complicated network regulating energy utilization and storage in myocardium is correlated with peraxisome prolifratoractivated receptors (PPARs) $(7,8)$. They are ligand-activated transcription factors belonging to the nuclear hormone receptor superfamily, including three isoforms termed as PPAR $\alpha, \operatorname{PPAR} \delta / \beta$ 
(hereafter $\delta$ ) and PPAR $\gamma$ (9). PPARs are activated by their selected ligands and form heterodimerize with retinoid $\mathrm{X}$ receptors (RXRs), respectively (10). Then the heterodimer binds to peroxisome proliferator response elements (PPREs), specific sequences in their target genes, and causes transcriptional switch (Fig. 1). Control of FA consumption and storage is considered as a prior outcome of activated PPRE (11). Current review highlights and compares the role of PPAR $\alpha$ and PPAR $\delta$ in fatty acid oxidation (FAO) and DCM.

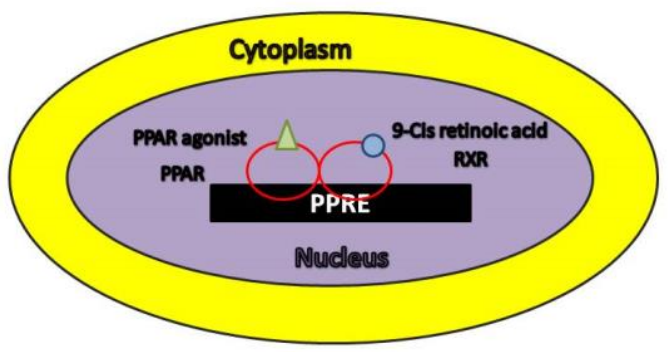

Figure 1 PPAR-RXR pathway: PPAR and RXRs coordinately regulate gene expression by means of forming heterodimers. The heterodimer binds to PPREs and exerts transcriptional effects.

\section{Pathophysiology of cardiomyopathy}

Heart is an organ with complicated cellular networks trying to maintain appropriate function. Despite all attempts, sometimes cardiomyocytes experience either revisable or unrevisable defaults leading to situation termed cardiomyopathy. Cardiomyopathy can occur as a result of mutation and extrinsic stimuli. Among 900 possible mutations affecting cardiomyocytes 400 mutations are tolerated by 13 sarcomeric proteins including $\beta$-myosin heavy chain $(\beta$ MyHC), $\alpha$-cardiac actin, tropomyosin, and troponin (12). Mutation in troponin complex, an essential modulator of $\mathrm{Ca}^{2+}$-stimulated actomyosin interaction or ATPase activity in the striated muscle, showed $\mathrm{Ca}^{2+}$-desensitization and decreased maximal force in group of patients suffering Cardiomyopathies (13). Extrinsic stimuli are another reason for cardiomyopathy. Doxorubicin is an antineoplastic agent causing cardiomyocytes experience pathogeny. Doxorubicin not only is a potent agent causing mutation, but also directly affects the function of a variety of proteins (14). It changes the activity of the oxidation-sensitive enzyme creatine kinase in a cardiomyocyte culture model (15) and causes inhibition of carnitine palmitoyl transferase-1 dependent long chain fatty acid (palmitate) oxidation (16).

Regarding to the reason of cardiomyopathy, patients are generally divided in two groups termed as primary and secondary cardiomyopathies. Primary cardiomyopathies includes disorders affecting the heart muscle, which have genetic, nongenetic, or acquired causes. Secondary cardiomyopathies expresses disorders that have myocardial damage because of systemic or multi-organ disease (17). There is also another characterization depending on the type of functional impairment of the 
cardiomyocytes including three groups; dilated, hypertrophic, and restrictive cardiomyopathies (18). Restrictive cardiomyopathy and Arrhythmogenic cardiomyopathy are two other groups added to this classification during recent years (17).

\section{Heart fuel utilization and diabetes}

The heart uses various substrates for energy metabolism, including glucose and FAs. Translocation of glucose transporters GLUT1 and GLUT4 to the cell membrane regulates glucose uptake (19). As GLUT1 is responsible for continuous basal glucose transport and GLUT4 is regulated by insulin and metabolic stress, GLUT4 function is affected in abnormal conditions. Another energy source is FA that is used as oxidative substrate in the adult heart. In healthy adult heart, FA oxidation provides $60-70 \%$ of the heart's ATP requirements (3-5), but according to availability and physiological needs, this percentage shifts between LCFAs and glucose substrate. Fetal heart, pumping blood in a relatively hypoxic environment, derives energy largely from the oxygensparing catabolism of glucose (20). Moreover, in some pathological conditions glucose precedes FAs, such as patients tolerating cardiac hypertrophy. On the opposite point, there are situations in which FAs are totalitarian sources of energy like DCM condition.

GLUT4 trafficking is stimulated by two different patterns known as PI3 Kinase dependent and independent pathways. PI3 Kinase dependent pathway is well documented as insulin sensitive pattern, but the correlation of IP3 Kinase independent pathway and insulin sensitivity is controversial (21). Thus, the dependent pattern is pointed as an effective factor in patients tolerating diabetes and insulin resistance.

Insulin binding to alpha subunit of insulin receptor (IR) is the first critical step in dependent pathway causing conformational changes in IR beta subunit leading to activation of IR intrinsic tyrosine kinase. The activated IR starts phosphorylation cascades via peptidase inhibitor 3 (PI3) Kinase phosphorylation. As a downstream event PI3 Kinase phosphorylates phosphatidylinositol 4,5-bisphosphate (PIP2) and forms Phosphatidylinositol $(3,4,5)$-trisphosphate (PIP3). PIP3 activate Pyruvate Dehydrogenase Kinase (PKD) 1 and mammalian target of rapamycin (mTOR) which both subsequently phosphorylates AKT/protein kinase $\mathrm{B}$ (PKB). Akt is made up of 3 subtypes named AKT1, AKT2 and AKT3. AKT2 continues the cascade by stimulating AKT Substrate of $160 \mathrm{KDa}$ (AS160) which acts as GTPase Activating Protein (GAP) for Rab protein (22). At last phosphorylated Rab protein stimulates GLUT4 to be expressed on the plasma membrane (23).

All this processes occur in insulin sensitive cells, but diabetes and insulin resistance can block this pattern at initiating level. Another underlying 
mechanism is related to the induction of inhibitory factors such as suppressors of cytokine signaling (SOCS). SOCS proteins block insulin signaling via competition with insulin receptor substrate (IRS)-1. Finally, increased activity of phosphatases which dephosphorylate intermediate signaling molecules can inhibit the insulin pathway (24). Taken together and as a result of insulin resistance GLUT4 trafficking is diminished and cardiomyocytes utilize FAs chiefly.

In diabetic cardiomyopathy, myocytes use LCFAs predominantly, therefore lipid metabolites are accumulated. Accumulation of lipid intermediates like diacylglycerol (DAG) is known to activate kinases such as PKC (25-28). As PKC is divided to three subgroups and each subgroup includes isotypes, they exert complicated effect in insulin pathway (29). Among isotypes, PKC $\theta$ and $\mathrm{PKC} \varepsilon$ clearly play a negative role in insulin pathway activation (30,31). PKC $\theta$ not only can phosphorylate IRS directly (32), but also through intermediates. As indirect role, $\mathrm{PKC} \theta$ activates stress Kinases $\mathrm{IkB} \alpha$ Kinase $\beta$ (IKK $\beta$ ) and c-Jun NH2-terminal Kinase (JNK) phosphorylating IRS and suppress insulin pathway (33). PKC can inhibit IRS via direct association with IRS (34) and also through direct phosphorylation (35). Another lipid intermediate produced through FAO pathway is ceramide. It can induce insulin resistance at the level of Akt inhibition (36,37). Pharmacological inhibition of ceramide synthesis has presented an effective role in preventing lipid-induced insulin resistance in rats. As ceramides are synthesized through denovo pathway in cardiomyocytes (38), pharmacological inhibition is required for this pathway. Denovo begins with the transfer of a serine residue onto a fatty acyl-CoA via serine palmitoyltransferase (SPT) (39) to form dihydrosphingosine which is converted to dihydroceramide via Ceramide synthase 4 (CerS4). On the other hand, CerS4 also uses preferential substrate that is provided via fatty acid elongase 6 (Elovl-6) to synthesize dihydroceramide. As the final step dihydroceramide changes to ceramide. Myriocin, a drug originated from Chinese traditional medication, is an example of pharmacologic ceramide inhibitor exerting selective inhibition on SPT leading to reduction of ceramide synthesis $(39,41)$.

As a result of surplus FA consumption and blocked glucose pathway, it is plausible that cardiomyocytes experience lipotoxicity through oxidative stresses. Thus, it is important to find some metabolic controller in order to prevent probable risks.

PPAR, PPAR $\delta$, two members of PPAR family

PPARs include three subtypes termed PPAR $\alpha, \operatorname{PPAR} \delta$ and PPAR $\gamma$. The subtypes have different characteristics including structure, tissue distribution, function and other features. From1990 up to recent years PPAR $\gamma$ was discussed in detail, but less is known about other 
subtypes, especially PPAR $\delta$. PPAR structure is formed by slices including $\mathrm{NH} 2$ terminal, DNA binding domain (DBD), hinge region and $\mathrm{C}$ terminal. $\mathrm{NH} 2$ terminal mediates ligandindependent transcriptional activation, DBD indicates PPRE and $\mathrm{C}$ terminal encompasses ligand binding domain. Each slice has a unique pattern in PPAR $\alpha$ and PPAR $\delta$ (Fig. 2) (42).

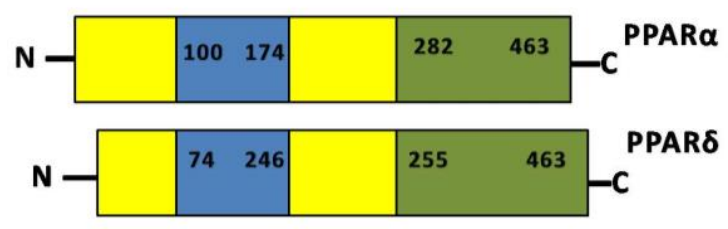

Figure 2 Schematic representation of PPAR $\alpha$ and PPAR $\delta$ protein domain. The numbers shown in the LBD and DBD refers to the number of aminoacids identified in PPAR $\alpha$ and PPAR $\delta$.

As different structure leads to different function and PPARs distribution is correlated with their function, each subtype fallows specific distribution pattern. PPAR $\alpha$ is mainly distributed in tissues with high capacity for fatty acid oxidation pathway such as heart, brown adipose tissue, skin, slow-twitch skeletal muscle and liver (43-45). PPAR $\delta$ is expressed predominantly in brain (46), adipose tissue, skin (45) and heart $(47,48)$. Between these subtypes, PPAR $\alpha$ is highly presented in liver and there are only some traces of PPAR $\delta$ in hepatocytes (49). PPAR $\alpha$ is coexpressed with CYP4A enzymes in this tissue. It binds to PPRE in the P4504A1 and 4A6 genes resulting in enzyme induction. Despite PPAR $\alpha$, PPAR $\delta$ seems to have no regulating effects on the expression of CYP4A or any other P450 enzyme (50). Considering P450 enzymes and especially CYP4A are responsible for many drugs and other substrates metabolization, it is important to recognize their common ligands. Fibrates are considered as the oldest PPAR $\alpha$ agonist. Natural carotenoid abundant in seafood can also stimulate PPARa (51). AVE8134 is another PPAR $\alpha$ agonist newly found in 2012 and has amazing features (52). Unlike PPAR $\alpha$, PPAR $\delta$ agonist is not well-known. GW50156 is an example of PPAR $\delta$ agonist employed in last decade. As GW50156 was plausible to contribute to carcinogenesis and also athlete abuse, now it does not seem to be a good choice(53).

Similarly to structure and tissue distribution PPRs functions can be analyzed. PPAR $\alpha$ agonist (54) reduces serum triglycerides (TG) and increases high density lipoprotein (HDL), but they also shows carcinogenic outcomes in rodents. Similarly PPAR $\delta$ activation causes reduction and elevation of $\mathrm{TG}$ and HDL in serum, respectively. This activation also triggers thermogenesis, weight loss and other metabolic possess $(55,56)$. Glucose utilization and FAO, two main important sources of energy satisfying cellular metabolic demands, are strongly related to PPAR managements. Cardiomyocytes are very critical cells affected by PPARs function via metabolic controls (57). 
PPAR alpha and metabolism in cardiac cell

Studies have demonstrated a serious role for PPAR $\alpha$ by means of transcriptional control on genes involved in cardiac FA uptake and oxidation (58,59). In the heart, activation of PPAR $\alpha$ increases the expression of genes participating to cellular FA utilization pathway in three major steps in the including fatty acid transport and esterification $(60,62)$, FA mitochondrial import (63), mitochondrial (62) and peroxisomal $\beta$ oxidation (Fig. 3) (64). Transporters and enzymes known to be regulated by PPAR $\alpha$ are indicated by a star. Abbreviations: (CPT I) carnitine palmitoyltransferase $\quad$ I; $\quad$ (CPT $\quad$ II) carnitine palmitoyltransferase II; (ACOX) acyl-CoA oxidase; (TCA) tricarboxylic acid.

Studies on PPARa null mice also emerged an inability to pay for increased cardiac workloads and depression of cardiac contraction occurs. PPAR $\alpha$-knockout mice display decreased cardiac FAO rates, but lipid uptake was presumably not affected, and cardiomyocyte lipid accumulation occurred. On the other hand, transgenic mice that over express PPAR $\alpha$ show an increase in the expression of genes encoding key enzymes involved in myocyte FA uptake and oxidation (65). Moreover, PPAR $\alpha$ activates pyruvate dehydrogenase kinase 4 (PKD4) (66). As PKD4 is responsible for phosphorylation of pyruvate dehydrogenase (PDH), activated PKD4 leads to inhibition of PDH (67). PPAR $\alpha$ also exert a role in glycolysis via elevated FA metabolites. Increased amount of citrate level as an outcome of elevated FAO pathway contributes to the inhibition of phosphofructokinase (PFK)-I resulting in suppression of glycolysis (68)

PPAR in cardiac cell

PPAR $\delta$ effect FA uptake negatively. FAs derived from serum TG, through lipo-proteinlipase (LPL) activation, seem to be the major source of FAO pathway (69). PPAR $\delta$ can suppress the LPL-mediated uptake of TG-derived through upregulation of angiopoietinlike 4 (Angptl 4) (70). Angptl 4 is a secreted protein which inhibits the LPL (71). PPAR $\delta$ is able to avoid lipid accumulation by means of carnitine palmitoyltransferase (CPT) I. CPT1 is located within the mitochondrial outer membrane as a rate-limiting enzyme of mitochondrial-oxidation by controlling mitochondrial entry of long-chain fatty acids. Both PPAR $\alpha$ and PPAR $\delta$ activate CPT1, but the importance is behind the majority. CPT1has three isoforms termed CPT1a, CPT1b, and CPT1c. CPT1b is the most predominant isoform and contributes $98 \%$ of total cardiac CPT1 activity. CPT1b is activated via $\operatorname{PPAR} \delta$ (72), whereas PPAR $\alpha$ activate CPT1a (67). Surprisingly, PPAR gamma co-activator (PGC)-1 $\alpha$ acts as co-activator for $\mathrm{PPAR} \delta$ in order to affect CPT1b (73). PGC-1 $\alpha$ also 


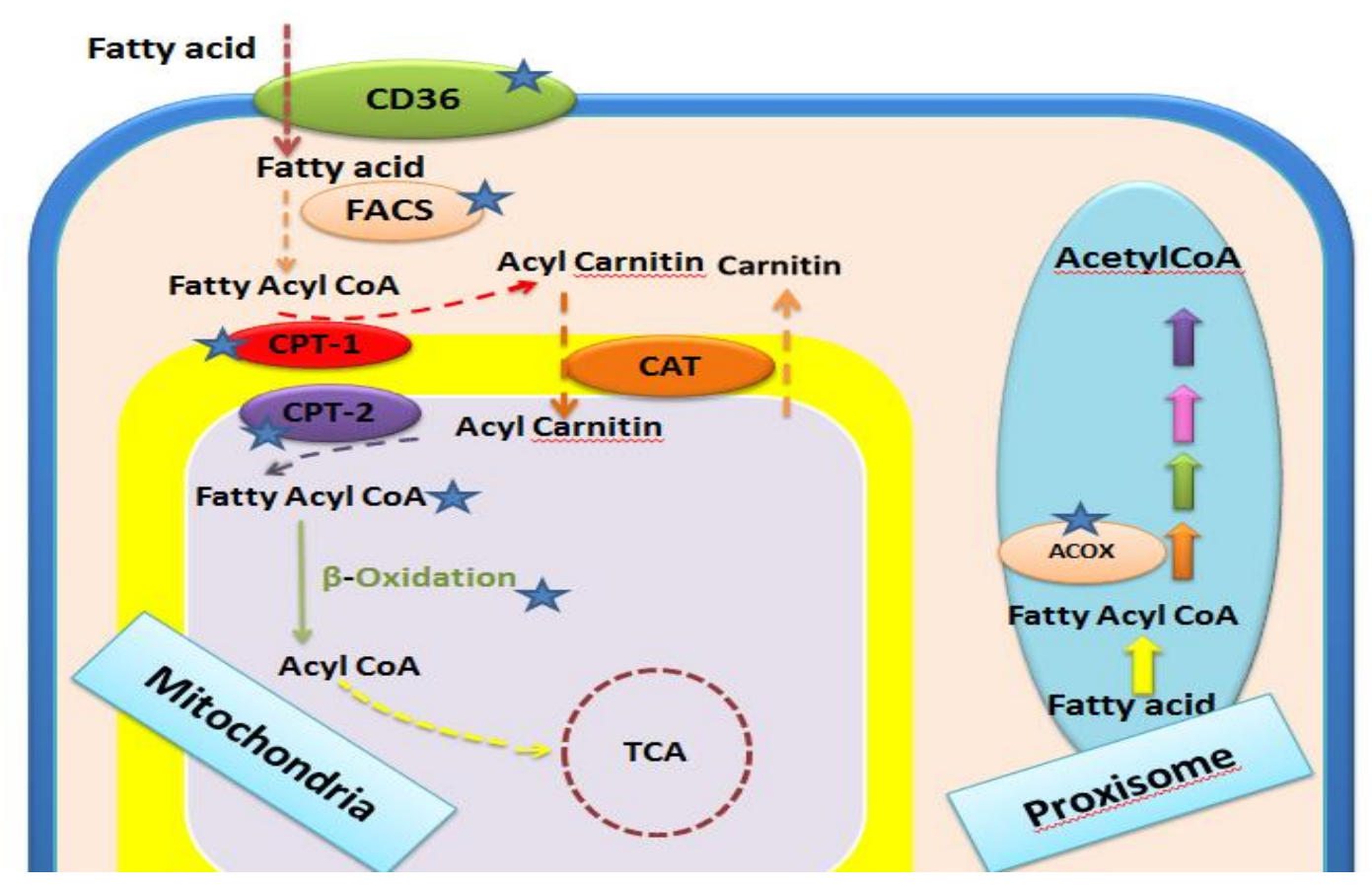

Figure 3 PPAR $\alpha$ targets in the cellular FAO pathway. Transporters and enzymes known to be regulated by PPAR $\alpha$ are indicated by a star. Abbreviations: (CPT I) carnitine palmitoyltransferase I; (CPT II) carnitine palmitoyltransferase II; (ACOX) acyl-CoA oxidase; (TCA) tricarboxylic acid.

accompanies PPAR $\delta$ for PKD4 activation (73).

\section{Conclusion}

As cardiomyocyes become insulin resistance in diabetes, glucose pathway is not passed properly. Thus, cardiac cells utilize fatty acids excessively in order to respond their need, but elevated rate of FA consumption creates positive feedback for FOA pathway mainly through IRS phosphorylation. PPAR $\alpha$ activation help cardiomyocytes to greet more FA from out of the cell via CD36 and increases available FAs. In the opposite point, PPAR $\delta$ suppress FA LPL-dependent uptake by activating Angptl4. PPAR $\delta$ helps ATP production via CPT1b. This transporter continues FOA pathway toward mitochondria for $\beta$-oxidation. Both PPAR $\alpha$ and PPAR $\delta$ activate PDK4. PDK4 inactivate Pyruvate Dehydrogenase (PDH) by means of phosphorylation. Thus, cardiomyocytes are forced to end glycolysis at aerobic point through lactate production.

\section{Conflict of interests}

Nothing to declare. 


\section{References}

1. Herlitz J, Malmberg K, Karlson BW, Ryden L, Hjalmarson A. Mortality and morbidity during a five-year follow-up of diabetics with myocardial infarction. Acta Med Scand 1988;224:31-8.

2. Shaw JE, Sicree RA, Zimmet PZ. Global estimates of the prevalence of diabetes for2010 and 2030. Diabetes Res Clin Pract 2010;87:4-14.

3. Bing RJ, Siegel A, Ungar I, Gilbert M. Metabolism of the human heart. II. Studies on fat, ketone and amino acid metabolism. Am J Med 1954;16:504-15.

4. Van der Vusse GJ, Glatz JF, Stam HC, Reneman RS. Fatty acid homeostasis in the normoxic and ischemic heart. Physiol Rev 1992;72: 881-940.

5. Lopaschuk GD. Metabolic abnormalities in the diabetic heart. Heart Failure Rev 2002;7:149-59.

6. Bertrand L, Horman S, Beauloye C, Vanoverschelde JL. Insulin signaling in the heart. Cardiovasc Res 2008;79:238-48

7. Finck BN. The PPAR regulatory system in cardiac physiology and disease. Cardiovasc Res 2007;73: 269-77.

8. Saunders J, Mathewkutty S, Drazner MH, McGuire DK. Cardiomyopathy in type 2 diabetes: update on pathophysiological mechanisms. Herz 2008;33:184-90.

9. Neher MD, Weckbach S, Huber-Lang MS, Stahel PF. New insights into the role of peroxisome proliferator-activated receptors in regulating the inflammatory response after tissue injury. PPAR Res 2012;2012: 728461.

10. DiRenzo J, Söderstrom M, Kurokawa R, Ogliastro MH, Ricote M, Ingrey S, Hörlein A, MRosenfeld MG, Glass CK. Peroxisome proliferator-activated receptors and retinoic acid receptors differentially control the interactions of retinoid $\mathrm{X}$ receptor heterodimers with ligands, coactivators, and corepressors. Mol Cell Biol 1997;17: 2166-76.

11. Varga T, Czimmerer Z, Nagya L. PPARs are a unique set of fatty acid regulated transcription factors controlling both lipid metabolism and inflammation. Biochim Biophys Acta 2011;1812:1007-22.

12. Harvey PA, Leinwand LA. The cell biology of disease: cellular mechanisms of cardiomyopathy. J Cell Biol 2011;194: 355-65.

13. Arimura $\mathrm{T}$, Hayashi $\mathrm{T}$, Kimura $\mathrm{A}$. Molecular etiology of idiopathic cardiomyopathy. Acta Myol 2007; 26:1538.

14. Umlauf J, Horký M. Molecular biology of doxorubicin-induced cardiomyopathy. Exp Clin Cardio 2002;7:35-9.

15. DeAtley SM, Aksenov MY, Aksenova MV, Jordan B, Carney JM, Butterfield DA. Adriamycin-induced changes of creatine kinase activity in vivo and in cardiomyocyte culture. Toxicology 1999;1:51-62.

16. Abdel-aleem S, el-Merzabani MM, SayedAhmed M, Taylor DA, Lowe JE. Acute and chronic effects of adriamycin on fatty acid oxidation in isolated cardiac myocytes. J Mol Cell Cardiol 1997;2:789-97.

17. Sisakian H. Cardiomyopathies: Evolution of pathogenesis concepts and potential for new therapies. World J Cardiol 2014;6:47894.

18. Report of the WHO/IFSC Task Force on the Definition and Classification of Cardiomyopathies. $\mathrm{Br}$ Heart J 1980; 44:672-3.

19. Bryant NJ, Govers R, James DE. Regulated transport of the glucose transporter GLUT4. Mol Cell Bio Rev 2002;3:267-77

20. Breckenridge RA, Piotrowska I, Ng EG, Ragan TJ, West JA, Kotecha S, et al. Hypoxic regulation of handa1 controls the fetal-neonatal switch in cardiac metabolism. PLoS Biol 2013;11: e1001666.

21. Sophie E L, Tavare JM. The molecular basis of insulin-stimulated glucose uptake: signalling, trafficking and potential drug targets. J Endocrinol 2009;203:1-18.

22. Mîinea $\mathrm{CP}$, Sano $\mathrm{H}$, Kane $\mathrm{S}$, Sano $\mathrm{E}$, Fukuda M, Peränen J, Lane WS, Lienhard 
GE. AS160, the Akt substrate regulating GLUT4 translocation, has a functional Rab GTPase-activating protein. Biochem J 2005;391:87-93.

23. Peck GR, Chavez JA, Roach WG, Budnik BA, Lane WS, Karlsson HK, Zierath JR ,Lienhard GE. Insulin-stimulated phosphorylation of the Rab GTPaseactivating protein TBC1D1 regulates GLUT4 translocation. J Biol Chem 2009; 284:30016-23.

24. Meshkani R, Adeli Kh. Mechanisms linking the metabolic syndrome and cardiovascular disease: role of hepatic insulin resistance. J Teh Univ Heart Ctr 2009;2:77-84.

25. Yu C, Chen Y, Cline GW, Zhang D, Zong $\mathrm{H}$, Wang $\mathrm{Y}$, et al. Mechanism by which fatty acids inhibit insulin activation of insulin receptor substrate-1 (IRS-1)associated phosphatidylinositol 3-kinase activity in muscle. J Biol Chem 2002; 277:50230-6.

26. Bandyopadhyay GK, Yu JG, Ofrecio J, Olefsky GM. Increased malonyl-CoA levels in muscle from obese and type 2 diabetic subjects lead to decreased fatty acid oxidation and increased lipogenesis; thiazolidinedione treatment reverses these defects. Diabetes 2006;55:2277-85.

27. Wang, S.P. Devaiah, W. Zhang, R. Welti, Signaling functions of phosphatidic acid, Prog. Lipid Res 2006;45:250-78.

28. Schenk S, Saberi M, Olefsky JM. Insulin sensitivity: modulation by nutrients and inflammation, J Clin Invest 2008;118: 2992-3002.

29. Turban S, Hajduch E. Protein kinase C isoforms: mediator of reactive lipid metabolites in development of insulin resistance. FEBS Letters J 2011;585:26974.

30. Samuel VT, Peterson KF, Shulman GI. Lipid induced insulin resistance: unravelling the mechanism. Lancet $\mathrm{J}$ 2010;375:2267-77.

31. Idris I, Gray S, Donnelly R. Protein kinase $\mathrm{C}$ activation: isosyme specific effects on metabolism and cardiovascular complications in diabetes. Diabetologia J 2001; 44: 659-73.

32. Li YT, Soos TJ, Li X, Wu J, Degennaro M, sun $\mathrm{X}$, et al. Protein kinase $\mathrm{C}$ teta inhibit signaling by phosphorylating IRS- 1 at Ser(1101). J BioChem 2004;279:45304-7.

33. Werner ED, Lee J, Hansen L, Yuan M, Shoelson SE. Insulin resistance due to phosphorylation of insulin receptor substrate-1 at serine 302. J Bio Chem 2004; 279:35298-305.

34. Ikeda Y, Olsen GS, Ziv E, Hansen LL, Busch AK, Hansen BF, Shafrir E, MosthafSeedorf L. Cellular mechanism of nutritionally induced insulin resistance in psommomys obesus: overexpression of protein kinase cepsilon in skeletal muscle preceeds the onset of hyperinsulinemia and hyperglycemia. Diabetes 2001;50:584-92.

35. Mack E, Ziv E, Reuveni H, Kalman R, Niv MY, Jorns A, Lenzen S, Shafrir E. Prevention of insulin resistance and bettacell loss by abrobating by PKC epsiloniInduced serine phosphorylation of muscle IRS-1 in psommomys Obesus. Diabetes Metab Res Rev 2008;24:577-84.

36. Stratford, D.B. DeWald, S.A. Summers, Ceramide dissociates 3'-phosphoinositide production from pleckstrin homology domain translocation, Biochem J 2001; 354: 359-68.

37. Holland WL, Brozinick JT, Wang LP, Hawkins ED, Sargent KM, Liu Y, Narra K, Hoehn KL, Knotts TA, Siesky A, Nelson DH, Karathanasis SK, Fontenot JK, Birnbaum MJ, Summersm SA. Inhibition of ceramide synthesis ameliorates glucocorticoid-, saturated-fat-, and obesityinduced insulin resistance. Cell Metab 2007;5:167-79.

38. Azzam R, Hariri F, El-Hachem N, Kamar A, Dbaibo G, Nemer G, Bitar F. Regulation of de novo ceramide synthesis: the role of dihydroceramide desaturase and transcriptional factors NFATC and hand2 in the hypoxic mouse heart. DNA Cell Biol 2013;32:310-9.

39. Holland WL, Summers SA. Sphingolipids, insulin resistance, and metabolic disease: new insights from in vivo manipulation of sphingolipid metabolism. Endocr Rev 2008;29:381-402.

40. Kurek K, Wiesiołek-Kurek P, Piotrowska DM, Lukaszuk B, Chabowski A, Żendzianendzian-Piotrowska M. Inhibition of ceramide de novo synthesis with myriocin affects lipid metabolism in the liver of rats with streptozotocin-induced 
type 1 diabetes. Biomed Res 2014; 2014:110.

41. Ruping J, Hirokazu A, Hongfeng J, Isaac G, Shunichi H, Yan L, et al. Inhibition of ceramide synthesis by myriocin inhibits cardiac remodeling, apoptosis and proteolysis in doxorubicin-induced cardiomyopathy. Circulation 2013;128: A15891.

42. John MW, David JC, Stephen AM, Jonathan PL, Ashley EB, Pat RR et al.

The chemical basis of serine palmitoyltransferase inhibition by myriocin. J Am Chem Soc 2013;135 :14276-85.

43. Motojima K. Proxisome prolifrator activated receptor: structure, mechanism of action and divers functions. Cell Struct Funct 1993:18:267-77.

44. Braissant O, Foufelle F, Scotto C,Dauca M,Wahli W. Differential expressionof peroxisome proliferator-activated receptors (PPARs): tissue distribution of PPARalpha, -beta, and -gamma in the adult rat. Endocrinology 1996;137:354-66.

45. Mukherjee R, JowL, Noonan D, McDonnell DP. Human and rat peroxisomeproliferator activated receptors (PPARs) demonstrate similar tissue distributionbut different responsiveness to PPAR activators. J Steroid Biochem MolBiol 1994;51:157-66.

46. Sertznig P, Seifert M, Tilgen W, Reichrath J. Proxisome prolifrative-activated receptors (PPARs) and the human skin. Am J Clin Dermatol 2008:9:15-31.

47. Kalinin S, Richardson JC, Feinstein DL. A PPARdelta agonist reduces amyloid burden and brain inflammation in transgenic mouse model of Alzheimer's disease.Curr Alzheimer Res 2009;6:431-7.

48. Chen ZC, Lee KS, Chen LJ, Wang LY, Niu HS, Cheng JT. Cardiac peroxisome proliferator-activated receptor $\delta$ (PPAR $\delta$ ) as a new target for increased contractility without altering heart rate. PLoS One 2013;8:e64229.

49. Ping $\mathrm{Ch}$, Li-Jen C, Juei-Tang C. Role of peroxisome proliferator-activated receptors $\delta$ (PPAR $\delta$ ) in rats showing endotoxemic heart failure. J Appl Biomed 2014;12:7985 .
50. Evans RM, Barish GD, Wang YX. PPARs and the complex journey to obesity.Nature Medcine 2004:10:355-61.

51. Pauie R.Otiz de Montellano. Cytochorome P450:Structure, mechanism and biology.Third Edition. Kluwer Academic/Plenum publisher. 2005: p.332.

52. Jia Y, Kim JY, Jun HJ, Kim SJ, Lee JH, Hoang $\mathrm{MH}$, et al. The natural carotenoid astaxanthin,a PPAR $\alpha$ and PPAR $\gamma$ agonist, reduces hepatic lipid accumulationby rewiring the transcriptome in lipid loaded hepatocytes. Nui Nutr Food Res 2012;56: 878-88.

53. Schafer HL, Linz W, Falk E, Glien M, Glombic H, Korn M, et al. VE8134 a novel potent PPAR- $\alpha$ agonist, improve lipid profile and glucose metabolism in dyslipdemic mice and type 2 diabetes. Acta Pharmacologia Sinica 2012;33:82-90.

54. Jihan Y, Mostafa B. Peroxisome proliferator-activated receptors and cancer: challenges and opportunities. $\mathrm{Br} \quad \mathrm{J}$ Pharmacol 2011;164:68-82.

55. Kersten S, Desvergne B, Wahli W. Role of PPARs in health and disease. Nature 2000; 405:421-4.

56. Kota BP, Huang TH, Roufogalis BD. An overview on biological mechanisms of PPARs. Pharmacol Res 2005;51: 85-94.

57. Wanger KD, Wanger N. Proxisome ProlifratorActivated beta/delta.(PPARbeta/delta)act as regulator of metabolism linked to multiple cellular functions. Pharmacol Thre 2010;125:423-35.

58. Fink BN. The PPAR regulatory system in cardiacphysiology and disease. Cardiovasc Res 2007;73:269-77.

59. Barger PM, Kelly DP. PPAR signaling in the control of cardiac energy metabolism. Trends Cardiovasc 2000;10:238-45.

60. Gilde, AJ, van der Lee KA, Willemsen PH, Chinetti G, van der Leij,et al. Peroxisome proliferatoractivated receptor (PPAR) alpha and PPARbeta/delta, but not PPARgamma, modulate the expression of genes involved in cardiac lipid metabolism. Circ Res 2003;92:518-24.

61. Motojima K, Passilly P, Peters JM, Gonzalez FJ, Latruffe N. Expression of putative fatty acid transporter genes are regulated by peroxisome proliferatoractivated receptor alpha and gamma 
activators in a tissue and inducer-specific manner. J Biol Chem 1998;273:16710-4.

62. Van Bilsen M, De Vries JE, Van der Vusse GJ. Long-term effects of fatty acids on cell viability and gene expression of neonatal cardiac myocytes. Prostagl Leukot Ess Fatty Acids 1997;57:39-45.

63. Van der Lee KA, Vork MM, De Vries JE, Willemsen PH, Glatz JF, Reneman RS, et al. Long-chain fatty acid-induced changes in gene expression in neonatal cardiac myocytes. J Lipid Res 2000;41:41-7.

64. Brandt J, Djouadi F, Kelly DP. Fatty acids activate transcription of the muscle carnitine palmitoyltransferase I gene in cardiac myocytes via the peroxisome proliferator- activated receptor $\alpha$. J Biol Chem 1998;273:23786-93.

65. Djouadi F, Brandt JM, Weinheimer CJ, Leone TC, Gonzalez FJ, Kelly DP. The role of the peroxisome proliferator- activated receptor $\alpha$ (PPAR) in the control of cardiac lipid metabolism. Prostagl Leukot Essent Fatty Acids 1999;60:339-43.

66. Finck BN, Lehman JJ, Leone TC, Welch ML, Be Annett MJ, Kovacs A,et al. The cardiac phenotype induced by PPAR $\alpha$ overexperession mimics that caused by diabetes mellitus. J Clin Invest 2002; 109:121-30.

67. Song $S$, Attia RR, Cannaughton $S$, Niesen MI, Ness GC, Elam MB, et al. Proxisome proliferator actuvated receptor alpha (PPARalpha) and PPAR gamma coactivator (PGC-1alpha) induce carnitine palmitoyltransferase1A(CPT-1A)via independent gene elements. Moll Cell Endocrinol 2010;30:351-2.

68. Zhang Sh, Hulver MW, McMillan RP, Cline MA, Gilbert ER. The pivotal role of pyruvate dehydrogenase kinases in metabolic flexibility. Nutrition \& Metabolism 2014; 11:10.
69. Turan B, Dhalla NS. Diabetic Cardiomyopathy:Biochemical and Molecular Mechanisms. 2014 Springer:, p.67.

70. Augustus AS, Kako Y, Yagyu H , Goldberg IJ. Routes of FA delivery to cardiac muscle: modulation of lipoprotein lipolysis alters uptake of TG-derived FA. Am J Physiol Endocrinol Metab 2003; 284:331-9.

71. Robciuc MR, Skrobuk P, Anisimov A, Olkkonen VM, Alitalo K, Eckel RH, et al. Angiopoietin-like 4 mediates PPAR Delta effect on lipoprotein lipase-dependent fatty acid uptake but not on beta-oxidation in myotubes. PLoS One 2012;7:e46212.

72. Gray NE1, Lam LN, Yang K, Zhou AY, Koliwad S, Wang JC. Angiopoietin-like 4 (Angptl4) protein is a physiological mediator of intracellular lipolysis in murine adipocytes. J Biol Chem 2012;287:844456.

73. He L, Kim T, Long Q, Liu J, Wang P, Zhou $\mathrm{Y}$, et al. Carnitine palmitoyltransferase- $1 \mathrm{~b}$ deficiency aggravates pressure overloadinduced cardiac hypertrophy caused by lipotoxicity. Circulation 2012;126:1705-16.

74. Kleiner S, Tran VN, Baré O, Huang X, Spiegelman B, Wu Z. PPAR $\delta$ Agonism activates fatty acid oxidation via PGC- $1 \alpha$ but does not increase mitochondrial gene expression and function. $\mathrm{J}$ Biol Chem 2009;284:18624-33. 